\title{
SUNCT syndrome: The materialization of a headache syndrome
}

\section{Ottar Sjaastad}

Department of Neurology, St. Olav's Hospital, 7006 Trondheim University Hospitals, Trondheim, Norway
Correspondence: Ottar Sjaastad Department of Neurology, St. Olav's Hospital, 7006 Trondheim University Hospitals, Trondheim, Norway Tel +47 73525276

Email eylert.brodtkorb@ntnu.no

\begin{abstract}
Shortlasting, unilateral, neuralgiform headache attacks with conjunctival injection and tearing (SUNCT) syndrome is a rare headache, described by our group in 1989. This overview presents our early studies of SUNCT pathogenesis. Due to the conspicuous ictal, ocular phenomena, ie, conjunctival injection and tearing, our studies started out with ocular parameters: intraocular pressure and corneal indentation pulse amplitudes, both of which showed clear ictal increments, symptomatic side. Beat-to-beat, noninvasive blood pressure measurements during attack showed instant, systolic blood pressure rise and corresponding pulse rate decrease. Carotid body, the principal peripheral chemoreceptor, seemed to function normally. The middle cerebral artery was dilated during attacks, particularly on the symptomatic side. Finally, some viewpoints are added regarding terminology. SUNCT is a workable and accepted term. There does not seem to be any need for another, fictitious term to describe the same clinical picture.

Keywords: SUNCT syndrome, intraocular blood flow, intraocular pressure, median artery blood flow, carotid body function, hypothalamic stimulation
\end{abstract}

\section{Introduction}

SUNCT is an abbreviation for shortlasting, unilateral, neuralgiform headache attacks with conjunctival injection and tearing. This communication describes how SUNCT was detected and defined (Sjaastad et al 1989). Studies conducted by our group, largely initiated and partly also completed at an early stage, will be reviewed. In doing so, a tribute will be paid to fellow investigators. No authentic review exists of these studies. Since we were the ones who described SUNCT syndrome, some thoughts about of the term per se are added.

SUNCT generally lends itself to purposeful exploration of pathogenetic mechanisms because of frequent shifts from pain freedom to pain phase. Contrarily, the brevity of solitary paroxysms (not infrequently only 10-20 seconds long) may hamper collection of scientific data.

For a sophisticated ocular parameter, like corneal indentation pulse (CIP) amplitudes, bilateral measurements could only occasionally be obtained during a solitary attack. The scarcity of SUNCT patients is also a hindrance, as is the eventual annoyance of the patients because of the massiveness of the imposed tests. These facts explain the relatively low number of tests for some of the variables.

\section{The first case}

The first SUNCT patient was observed in 1977, at 62 years of age. At around 30, this male patient had developed cycles of unilateral, ocular/periorbital, mostly low-grade pain (Sjaastad et al 1978; 1989). The headache seemed rather stable at this level until he, at 58 , was struck by the end of a fishing rod in the lower, medial, supraorbital area on the symptomatic side. Afterwards, there was a multiplicity of shortlasting, mostly mechanically provoked, more severe paroxysms, still with a fluctuating course (Sjaastad et al 1989). 
The paroxysms were from then on accompanied by conjunctival injection, lacrimation, and rhinorrhea. Attacks could be provoked mechanically. There seemed to be only a minimal, postictal refractory period. The trauma had apparently been mild. However, at that time, the role of the trauma could not be determined. We, therefore, had to wait for the next, similar patient to rule out the faint possibility of a posttraumatic headache. That took approximately 10 years. In the meantime, studies regarding pathogenesis were made on this patient (later on, on three patients [Sjaastad et al 1989] and finally, on six patients).

\section{Diagnosis and differential diagnosis}

The critical diagnostic features of SUNCT syndrome are: unilateral headache, high number of shortlasting attacks, and autonomic features, in particular conjunctival injection, tearing, and rhinorrhea. Whether mechanical precipitation of attacks, postictal refractory period and other characteristics, eg, hypernea and abrupt blood pressure augmentation, can be used diagnostically is more uncertain at the present time.

The differential diagnosis vs. the other unilateral headaches, such as chronic paroxysmal hemicrania (CPH), cluster headache, and trigeminal neuralgia was worked out prior to the mid-90s, ie, as soon as it was ascertained that a posttraumatic headache could be excluded. Except for the observation of symptomatic SUNCT cases (Bussone et al 1991), there have been few systematic appendages to the original clinical description.

\section{Studies on pathogenesis Intraocular variables Intraocular pressure}

It was natural to start with ocular parameters when trying to disentangle the pathogenesis. Intraocular pressure (IOP) was measured by both the applanation tonometer and the dynamic tonometer. The latter is an improved, standardized, electronic Schiøtz tonometer, but with continuous recording at varying speed and with varying degree of pulse waves amplification (Hørven 1970). Ictal IOP in various headaches, measured by dynamic tonometry, is detailed in Table 1. Evidently, there was clear IOP increment, symptomatic (S) side, during SUNCT attacks, as compared with the preictal level, the highest registered level being $20.6 \mathrm{~mm} \mathrm{Hg}$ (Sjaastad et al 1992). IOP may start increasing just prior to pain onset (Figure 1). IOP reached stable levels ca. 4 seconds after pain discontinuation.

As for applanation tonometry, there were a total of 48 observations in 6 patients (Sjaastad et al 1992). It demonstrated an invariable increment, $\mathrm{S}$ side, during attacks with 36 observations in 3 patients; mean increment: $2.6 \pm 0.85 \mathrm{~mm} \mathrm{Hg}$, vs. nonsymptomatic (NS) side: $0.5 \pm 0.02$ (unweighted values). During three attacks in two patients, IOP could be measured bilaterally, mean increment, $\mathrm{S}$ side: $2.5 \mathrm{~mm} \mathrm{Hg}$, vs. NS side: 0.7 . In the interictal period, there was a tendency to a relatively low IOP, $\mathrm{S}$ side; $\mathrm{S}$ side $<\mathrm{NS}$ side ( $\mathrm{P}=0.05$, Student's t-test). During attack, this asymmetry was evened out or overcompensated.

A meaningful number of attacks was studied by two different methods with an unequivocal result: an attackrelated IOP increment was invariably observed: $\mathrm{S}$ side $>\mathrm{NS}$ side. The conclusion can, nevertheless, probably be drawn that the increase in IOP does not cause the pain alone. It may be more like a parallel phenomen. The fact that IOP was appreciably lower during the initial pain phase than during the early postictal phase (in other words, with no pain) (Figure 1) to some extent counts in favour of this pathogenetic model.

\section{Corneal indentation pulse amplitudes}

Amplitudes were measured by dynamic tonometry (Hørven 1970). During eight attacks in two patients, the average ictal

Table I Intraocular pressure in various headaches (dynamic tonometry, in $\mathrm{mm} \mathrm{Hg}$ )

\begin{tabular}{lllllll}
\hline Groups & $\begin{array}{l}\text { No. } \\
\text { examinees }\end{array}$ & $\begin{array}{l}\text { Without attacks } \\
\text { S }\end{array}$ & NS & $\begin{array}{l}\text { Attacks } \\
\text { S }\end{array}$ & NS & $\begin{array}{l}\text { S side Ratio: } \\
\text { Attacks/no attacks }\end{array}$ \\
\hline Controls & 25 & $14.4 \pm 2.38$ & - & - & - & \\
Migraine & 12 & 14.5 & 14.5 & 14.2 & 14.6 & 1.0 \\
Cluster HA & 18 & $12.3 \pm 2.32$ & 12.1 & $13.7 \pm 4.32$ & $11.9 \pm 2.94$ & 1.1 \\
CPH & 7 & $15.2 \pm 3.06$ & - & $19.4 \pm 5.06$ & $17.3 \pm 3.53$ & 1.3 \\
SUNCT & I' & 9.8 & - & 15.6 & - & 1.6 \\
Applanation tonometry & 3 & $13.7 \pm 1.94$ & $14.4 \pm 2.58$ & 16.3 & 14.9 & 1.2 \\
\hline
\end{tabular}

Notes: 17 attacks.

Abbreviations: $\mathrm{CPH}$, chronic paroxysmal hemicrania; S, symptomatic side; NS, nonsymptomatic side. 


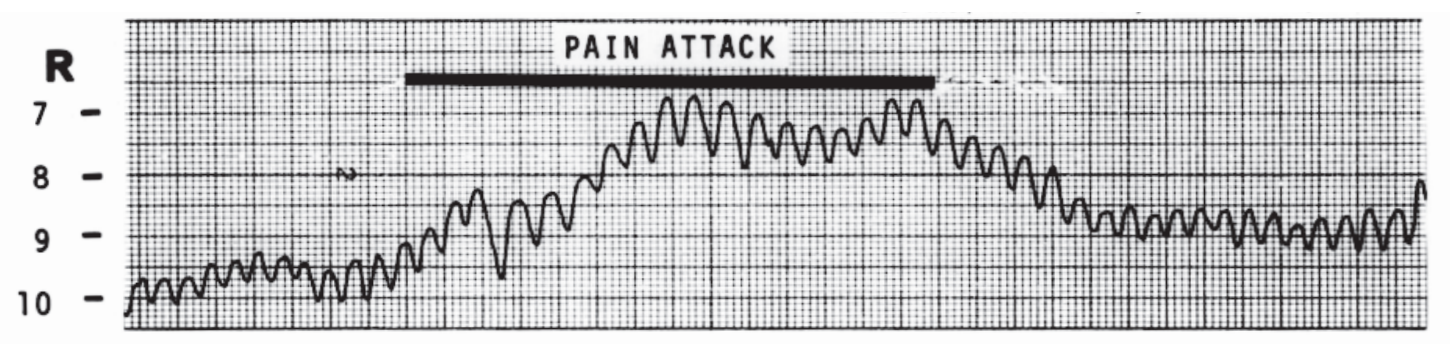

SENSITIVITY: 5 MILLIVOLTS/DIV.

SPEED: 5 MM/SECOND

Figure I Dynamic tonometry recording prior to, during, and following a pain paroxysm. Copyright @ I 992. Reproduced with permission from Sjaastad O, Kruszewski P, Fostad K, et al 1992. SUNCT syndrome:VII. Ocular and related variables. Headache, 32:489-95.

amplitude height, S side, was 44 my during attack (Table 2), an average increase of $138 \%$, compared with painfree period (range 88\%-167\%) (Sjaastad et al 1992). Control values were: $30.6 \pm 9.8$ my (Hørven et al 1989). The average percentage-wise increment thus seems to be larger than in any of the other studied headaches, inclusive of CPH (Table 2). The temporal aspects of IOP and corneal indentation pulse amplitude (CIP) curves were rather similar, with a tendency to preictal and postictal increments of both. In two attacks with continuous registration from the preictal stage (attack duration: ca.13-14 seconds), the peak of the IOP curve was reached after 7-10 seconds (Figure1). The amplitudes started increasing 2.5-3 seconds prior to pain onset and the increase lasted until 3.5-4 seconds after pain disappearance. Dynamic tonometry tracings can, therefore, probably herald a forthcoming attack. Ictal CIP amplitudes, NS side, have not been examined systematically. An asymmetry of $15 \%$ is reckoned as being abnormal (Hørven et al 1972). Outside attacks, values of $21 \mathrm{my}, \mathrm{S}$ side, and 17, NS side, respectively were observed on one occasion: an asymmetry of $24 \%$.

The bradycardia that accompanies the attacks (see later) cannot explain the ictal CIP increase.

In theory, the increase in both IOP and CIP could be due to increased tonus in the orbcularis oculi muscle owing to the level of pain? This muscle was, therefore, anesthetized $(\mathrm{n}=2$; tests $=4$; on one occasion, bilaterally). This procedure had no appreciable influence upon IOP/CIP, nor was the pain per se influenced.

Theoretically, there are then two ways to explain the abrupt, marked, and transitory IOP increment: It could be due to transitory production/conveyance abnormalities of the aqueous humor, or to intraocular, vascular changes. The average increment in IOP during attacks, $5.8 \mathrm{~mm} \mathrm{Hg}$ (Sjaastad et al 1992) was achieved within $\leq 10$ seconds. The normal production rate of aqueous humor is ca.
$3 \mathrm{~mm}^{3} /$ minute. The observed, ictal IOP increment corresponds to approximately $12 \mathrm{~mm}^{3}$ in intraocular volume increase, if the conversion tables of Langham and HetlandEriksen are employed (Hørven et al 1970). Interference with the normal conveyance of aqueous humor probably cannot, therefore, explain the IOP increment.

Average episcleral pressure, $\mathrm{S}$ side, changed only minimally during attacks in two patients (ictally: $7.5 \mathrm{~cm} \mathrm{H} \mathrm{H}_{2}$; tests $=10$; interictal phase: 7.2 ; tests $=13)($ Sjaastad et al 1992). There was no asymmetry outside attacks (tests $=7$ ) or in those measured bilaterality during attacks (tests $=2$ ). Gonioscopy was carried out during attack $(n=1)$. No signs of angle-closure glaucoma were detected.

The ictal IOP changes are accordingly most likely secondary to vascular changes, ie, a vasodilation. The abruptness and vehemence of the vascular phenomena, as well as the height of the amplitudes taken into consideration, vasodilation is more likely to occur on the arterial than on the venous side.

Based on intraocular volume change $(\Delta \mathrm{V})$ in $\mathrm{mm}^{3}$ and the exact pulse rate, the pulsatile ocular blood flow can be calculated (in $\mathrm{mm}^{3} / \mathrm{min}$ ). The flow ( $\Delta \mathrm{V}$ per minute) was ca. 300 during and 240 after attack, in one completely recorded attack (Sjaastad et al 1992).

\section{Corneal temperature}

Ictal, intraocular vasodilation might possibly be accompanied by corneal temperature increment, whereas such increment hardly would be consistent with aqueous humour abnormalities. Corneal temperature was, therefore, measured, with a special, sensitive probe (Hørven et al 1975) that could be placed onto the cornea after local anesthesia; a total of 25 measurements were carried out in 5 patients. During an attack-free period ( 8 measurements in 2 patients), there was no definite asymmetry. The average interictal temperature 
Table 2 Corneal indentation pulse (CIP) amplitudes in various headaches (in $\mu$ )

\begin{tabular}{|c|c|c|c|c|}
\hline Groups & No. examinees & $\begin{array}{l}\text { Outside attacks } \\
\text { S side }\end{array}$ & $\begin{array}{l}\text { During attacks } \\
\mathrm{S} \text { side }\end{array}$ & $\begin{array}{l}\text { S side } \\
\text { Ratio: } \\
\text { Attacks/no attacks }\end{array}$ \\
\hline Controls & 25 & $30.6 \pm 9.8$ & - & - \\
\hline Migraine & 12 & $25.1 \pm 4.4$ & $24.4 \pm 4.1$ & 0.97 \\
\hline Cluster headache & 18 & $23.6 / 23.0^{\prime}$ & 34.8 & 1.5 \\
\hline $\mathrm{CPH}$ & 7 & $33.4 / 31.3^{1}$ & $54.6 \pm 15.7^{2}$ & 1.6 \\
\hline SUNCT & $2^{3}$ & $19 / 17^{1}$ & 44 & 2.3 \\
\hline
\end{tabular}

Notes: 'S (symptomatic)side/NS (nonsymptomatic)side; ${ }^{2}$ Difference S/NS sides: $\mathrm{p}<0.005$, paired comparison; ${ }^{3}$ No. tests $=8$.

Abbreviation: $\mathrm{CPH}$, chronic paroxysmal hemicrania.

in a period with rare attacks, showed no asymmetry in one particular patient (tests $=4$ ), ie, $32.3^{\circ} \mathrm{C}$, S side, vs. $32.2^{\circ} \mathrm{C} \mathrm{NS}$ side. However, during attacks (tests $=3$ ) in the same patient, there was an appreciable average asymmetry: $34.9{ }^{\circ} \mathrm{C}, \mathrm{S}$ side; $34.2^{\circ} \mathrm{C}$, NS side. Outside attacks, but within a period of frequent attacks ( 8 measurements in 2 patients), there was a mean difference of $0.8^{\circ} \mathrm{C}$ ( $\mathrm{S}$ side invariably $>\mathrm{NS}$ side). In 40 healthy subjects, the mean corneal temperature was $33.74{ }^{\circ} \mathrm{C}$ and $33.67^{\circ} \mathrm{C}$, right and left sides, respectively (Hørven 1975). Temperature tracings can be interpreted with an accuracy of $0.1{ }^{\circ} \mathrm{C}$. An asymmetry of $0.6^{\circ} \mathrm{C}$ is considered as pathological. The asymmetry observed during attacks and interictally in periods with frequent attacks is, therefore, probably abnormal and consistent with intraocular vasodilation.

A similar temperature difference (mean $0.7{ }^{\circ} \mathrm{C}, \mathrm{n}=2$ ) was demonstrated ictally on the upper eyelids. No significant asymmetry was found on the lower eyelid or supraorbitally. The temperature increase thus seemed to be limited to orbital cavity proper and nearby structures. Interestingly, one study in trigeminal neuralgia generally showed lower facial temperature on the $\mathrm{S}$ than on the NS side $\left(\leq 0.8^{\circ} \mathrm{C}\right.$; Hardy et al $1989)$, in other words, it showed an opposite pattern.

\section{Pupillometry}

Ocular vascular phenomena appeared during attacks. Would there also be detectable abnormalities in other ocular "structures", such as the pupils? Pupillometry was carried out $(n=5)$ with the Whittaker (Gulf and Western, Boston, MA, USA) infrared, binocular pupillometer, with continuous TV-transmission and with a precision of $0.05 \mathrm{~mm}$ (Salvesen et al 1987). Unprovoked pupil widths averaged 4.7, S side, and $4.5 \mathrm{~mm}$, NS side (Zhao et al 1993). Asymmetries were $\leq 0.4 \mathrm{~mm}$ as a rule; one exception: 0.6 $\mathrm{mm}$, with the larger pupil, $\mathrm{S}$ side. The asymmetries in other words generally were within the control range (in our own series, $\leq 0.5 \mathrm{~mm}$ (Salvesen et al 1987). Moreover, there was no ptosis. Pharmacopupillometry was carried out (Zhao et al
1993): mainly topical administration of a directly acting, sympathicomimetic drug: phenylephrine $(1 \%)$ or an indirectly acting one: $\mathrm{OH}$-amphetamine $(1 \%)$. $\mathrm{OH}$-amphetamine showed lowered S/NS ratios (0.5 and 0.6$)$ for two of the five patients, but no tendency to a reverse response upon phenylephrine. The relative lack of pupillary dilation, $\mathrm{S}$ side, upon $\mathrm{OH}$-amphetamine could indicate a shortage of locally stored noradrenaline; but the lack of overreaction to the directly acting agent negates this alternative. There thus does not seem to be any clear trend as regards pupillometric findings. Topical administration of the antimuscarine agent, tropicamide $(n=2)$ did not add essential information. Pupillometry could only be carried out interictally. Because of this imperfection, substantial amount of information may have escaped.

\section{Corneal sensation}

Corneal sensation (Vijayan et al 1984) was tested with the Cochet-Bonnet esthesiometer (a $6.0 \mathrm{~cm}$ long, adjustable [6.0-0.5 cm] nylon monofilament, the pressure exerted by the tip of the filament being $11-200 \mathrm{mg} / \mathrm{mm}^{2}$ ). Control individuals feel the touch of the $6.0-\mathrm{cm}$ long monofilament. Corneal sensation between paroxysms was normal $(n=6$; tests $=10)$. During attacks, there was a sensory deficiency, $\mathrm{S}$ side $(\mathrm{n}=2$; tests $=6$ ); average length: $4.6 \mathrm{~cm}$, unweighted values, vs. $6.0 \mathrm{~cm}$, NS side. In the most-studied patient (tests $=5$ ), there were values down to $2.0 \mathrm{~cm}$, during attack, the lower values seemingly appearing during high intensity attacks. Based on the values obtained in this patient alone, two-sided Student's t-test showed significant difference between $\mathrm{S}$ and NS sides (Zhao et al 1993). The number of tests is scarce. Furthermore, in contradistinction to the aforementioned variables, this test is based upon the cooperation of the patient. Ongoing pain may have caused distraction. This should, however, also concern the NS side (where normal values were obtained). Furthermore, in cluster headache, where pain is assumed to be excruciating (Russell 1978), normal findings have been obtained by the same method (Vijayan et al 1984). 


\section{Changes outside orbita \\ Forehead sweating}

Would abnormalities also be detectable in nearby structures such as forehead sweat glands? Sweating was monitored in a room with a stable temperature: $27 \pm 1{ }^{\circ} \mathrm{C}$. Sweating was assessed by an evaporimeter (Nilsson 1977). At two set, perpendicularly arranged levels close to the skin surface, temperature and humidity are continuously measured, and from this information the instrument can calculate the vapour pressure gradient in a microclimate. In 25 control individuals, the mean sweating was $15.8 \mathrm{~g} / \mathrm{m}^{2} / \mathrm{h} \pm 5.1$ (range 2-28). Maximum control asymmetry, medial part of the forehead was $6 \mathrm{~g} / \mathrm{m}^{2} / \mathrm{h}$. (Sjaastad et al 1981).Visible sweating was present at around $90 \mathrm{~g} / \mathrm{m}^{2} / \mathrm{h}$.

Interictal sweating was within control limits $(\mathrm{n}=6)$ (Kruszewski et al 1993). Patients studied in a drug-free situation, during attack $(n=3$; tests $=64)$ showed increased sweating, mostly moderately so, medial part, forehead, $\mathrm{S}$ side. In the most-studied patient, ictal sweating on average was clearly increased, S side: $60 \pm 22.5$ (range 20-105); NS side; $20 \pm 4.0(13-26)($ tests $=28 / 11)(\mathrm{P}<0.0001$, Student's t-test). In one patient (tests $=11$ ), average ictal sweating, $\mathrm{S}$ side, was not increased in absolute values, but still clearly higher than on the NS side; S side: $14 \pm 5.6$ ( range 7-27) $\mathrm{g} / \mathrm{m}^{2} / \mathrm{h}$; vs. NS side: $7 \pm 1.8(5-11)$, respectively ( $\left.<<0.005\right)$; outside attacks: $7 \pm 2.5$, S side; $6 \pm 2.4$, NS side. Sweating on $\mathrm{S}$ side was significantly higher during than outside attacks. There was no sweating deficiency in the forehead, S side, during general body heating (Kruszewski et al 1993), as observed in cluster headache ( $86 \%$ of cases; Salvesen et al 1988). The reflex arch for sweating in the forehead thus seems to be intact in SUNCT. In keeping with this interpretation, there was symmetrical forehead sweating during direct, ie, pilocarpine stimulation (Kruszewski et al 1993). Ictal forehead sweating, S side, in SUNCT, therefore, probably means a direct stimulation of intact sweat glands without supersensitivity phenomena.

\section{Blood pressure and pulse rate}

Since marked intraocular, vascular changes occur ictally, what about the general circulation? Noninvasive, instant blood pressure (beat-to-beat, in correct time) could be monitored by a Doppler servo method (Aaslid and Brubakk 1981) ( $\mathrm{n}=2$; tests $=5$, during attacks; between attacks: 23 tests). Systolic blood pressure rose immediately and markedly during attacks (rise of approximately 8 and $18 \mathrm{~mm} \mathrm{Hg}$, respectively; Figure 2). (A third patient examined by the Korotkoff method showed the same tendency). The diastolic pressure rose correspondingly in one patient (Kruszewski et al 1991). There was a systematic, corresponding decrease in pulse rate (Figure 2). Immediately prior to attack, however, there seemed to be a pulse rate increase (Figure 2). The number of cases examined is restricted, but the pattern seemed stereotyped. If reproducible, these facts will have to be explained by any theory that aims at explaining SUNCT pathogenesis.

\section{Respiratory sinus arrhythmia}

During inspiration (I), blood is sucked into the heart: The $\mathrm{R}-\mathrm{R}$ distance is shortened, with heart rate increase. During expiration (E), the situation is reversed. Fluctuating parasympathetic activity is assumed to underlie this respiratory arrhythmia. During inspiration, impulses from stretch receptors in the lungs are conducted via vagal nerves to the cardioinhibitory area in the medulla oblongata, causing inhibition of the inhibitory centre. The expiration/inspiration (E:I) ratio connotes the ratio between the longest $\mathrm{R}-\mathrm{R}$ interval during expiration and the shortest R-R interval during inspiration. The E: 1 ratio was higher in SUNCT $(n=6)$, interparoxysmally $(1.32 \pm 0.12)$, than in controls $(n=9): 1.18 \pm 0.06$ ( $\mathrm{P}<0.02$, Mann-Whitney test). This could indicate vagal hyperactivity in SUNCT. During attacks, however (55 attacks in 3 patients), the ratio was significantly lowered, ie, down to control values (Kruszewski et al 1992). The latter finding, if anything, might indicate lowered ictal, vagal tone. The mechanisms underlying this fluctuation may be complex and should probably be viewed in the context of the abrupt, simultaneously occurring ictal changes in intraocular variables: IOP/CIP and also the increase in blood pressure and lowered pulse rate.

\section{Ventilation}

It was discovered clinically at the very outset that SUNCT patients have a slight hyperpnea during attack (Sjaastad et al 1989). Later, it was demonstrated that breaths/min amounted to16.2 \pm 3.8 , interictally (unweighted values) as against $19.0 \pm 5.0$, ictally $\left(\mathrm{P}<0.05\right.$, Student's t-test). End-tidal $\mathrm{PCO}_{2}$ was measured by a capnograph (Datex, Helsinki, Finland), (Kruszewski et al 1995). Average, interictal end-tidal $\mathrm{PCO}_{2}$ (kPa) amounted to $4.7 \pm 0.4$, as against $4.2 \pm 0.6$ ictally ( $\mathrm{P}<0.03$, paired Student's t-test) ( 25 tests in 4 patients). In two patients (tests $=11$ ), the ictal increment in minute ventilation was assessed: average 7.4 and 2.5 , respectively (in L/min). Moreover, the patients seemed to hyperventilate slightly interictally. In theory, the hyperpnea could be due to the pain, but, other, probably as bad, headaches are not known to be 
accompanied by hyperventilation (eg, migraine). Hyperventilation is more likely to be an integral part of the disorder.

\section{Oxygen saturation}

Arterial oxygen saturation $\left(\mathrm{SaO}_{2}\right.$ in $\left.\%\right)$ was at the same level ( $\mathrm{n}=4$, tests $=17$ ) prior to attacks as in five control individuals. There is thus no evidence that a relative lack of oxygen is present in SUNCT (and could have been a causative factor). Anoxemia has been suspected to be a causative factor in cluster headache, but has also in that headache been "exonerated" from that suspicion. Oxygen saturation increased slightly (94.9 vs. 95.8), but significantly (paired Student's t-test: $\mathrm{p}=0.02$ ) during attack (Kruszewski et al 1995).
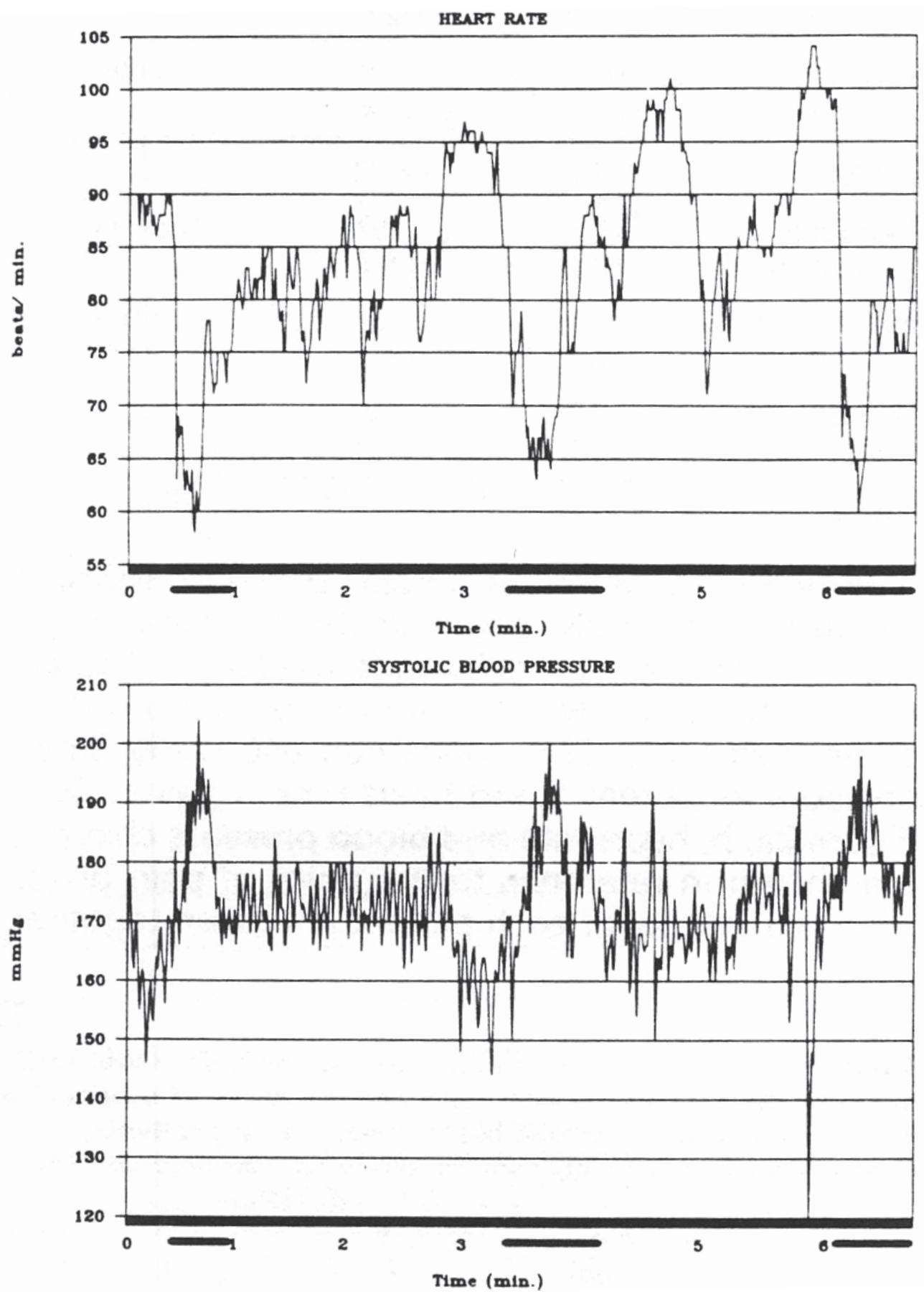

Figure 2 Heart rate (upper tracing) and systolic blood pressure (lower tracing) during three separate paroxysms (indicated by dark lines along the time axis). Copyright $@$ 1991. Reproduced with permission from Kruszewski P, Fasano M, Brubakk AO, et al. I99I. Short-lasting, unilateral neuralgiform headache attacks with conjunctival injection, tearing, and subclinical forehead sweating ("SUNCT syndrome): Il Changes in heart rate and arterial blood pressure during pain paroxysms. Headache, 31 :399-405. 


\section{Carotid body function}

Carotid body is the principal peripheral chemoreceptor. Two types of tests were carried out to assess its function in SUNCT. A. $100 \% \mathrm{~N}_{2}$ was inhaled, to bring oxygen saturation down to $\leq 80 \%$. B. Single breath inhalation of $13 \% \mathrm{CO}_{2}$ was applied to affect the blood oxygen content "appreciably" (Kruszewski et al 1995). More breaths of high concentration $\mathrm{CO}_{2}$ were not tried, because then the central chemoreceptor(s) could also be activated.

Ten tests were carried out in 5 patients. Ten control individuals, matched for age, sex, and smoking habits were also studied. There were no significant differences between the SUNCT and control groups as regards the response parameters generally (outside attacks, but in attack periods).

There was one single exception: Mean $\mathrm{CO}_{2}$ response, showed a significantly lowered value in SUNCT. This may suggest a blunted carotid body response. However, none of the other variables supported this conclusion.

Paroxsysms could start during these registrations, but there appeared to be no set relationship between lowered $\mathrm{O}_{2}$ staturation/altered $\mathrm{PCO}_{2}$ and onset of paroxysms.

\section{Intracranial parameters Ictal dynamic changes in blood flow velocity, middle cerebral artery}

Would vascular dynamics be changed even intracranially during attacks? Vasomotor activity in the intracranial arteries was tested by transcranial Doppler sonography (Aaslid et al 1982).The mean cerebral blood flow velocity was assessed in units of $\mathrm{cm}$. The vasomotor reactivity was determined as the percentage change in blood flow velocity upon reduction in end-tidal $\mathrm{PCO}_{2}$ (in $\mathrm{kPa}$ ), monitored by a capnograph (Shen et al 1993).

Middle cerebral artery (MCA) blood flow velocity $(n=4$; 8 spontaneous and 4 precipitated attacks) was clearly reduced already after 10 seconds of the pain attack; the lowest values were observed, $\mathrm{S}$ side, during the middle part of spontaneous attacks ( $\mathrm{P}<0.009$, Student's t-test). A lesser, but significant drop in blood flow velocity was also found, NS side (Shen et al 1993).

This time curve seemed to follow approximately the "intraocular parameters" curve with onset of changes after a few seconds and normalization steps upon discontinuation of pain. The findings indicate an abrupt, marked and shortlasting MCA vasodilatation. These attacks lasted somewhat longer than the attack recorded in Figure 1. The invariability of the MCA findings indicate that the cerebral circular abnormalities are integral components of SUNCT attack.

\section{SUNCT: The term and its contents - the future}

\section{Autonomic features}

SUNCT as such was included in the International Classification of Headaches Disorders, 2nd version, 2004; International Headache Society (IHS). Although the structure of the SUNCT classification is generally straightforward, it contains controversial details that will need some comment. As we see it, the triad of "local" autonomic phenomena, ie, conjunctival injection, tearing, and rhinorrhea seems to constitute cornerstones diagnostically, being present in 100\%/95\%/63\%, respectively in the first 21 patients (Pareja et al 1997). Conjunctival injection and tearing would accordingly be present in close to $100 \%$ of these cases. Rhinorrhea is also mentioned in the title "... tearing, sweating, and rhinorrhea" (Sjaastad et al 1989). All three features would thus be present in ca. $2 / 3$ of the cases. It was not the intention behind the term 'SUNCT' to demand that conjunctival injection and tearing invariably would be present in the individual patient. But it was the intention to indicate that, at least based on the early evidence (Sjaastad et al 1989), these two features seemed to have a cardinal position among the autonomic aberrations in SUNCT. Forehead "sweating" was also mentioned in the title, but sweating was only subclinical and accordingly useful only to the connoisseur. Other autonomic features, like hyperpnea, might also be of some diagnostic import. The number of solitary autonomic features may thus be four or five - or even more. The more autonomic features, the safer the diagnosis must be assumed to be.

The IHS Headache Classification (2004) presents two sets of criteria for SUNCT. The "regular criteria" (Table 3) contain only two autonomic features: conjunctival injection and tearing; the two items are connected with an "and" and not with "and/or". It is, in other words, claimed that they always are present together. The not too far-fetched possibility that conjunctival injection and tearing may appear separately has not been mentioned at all. This is actually a capital shortcoming. But then there appears to have been a complete change of mind, and it is stated - in a "Note" and in an "Appendix" - that these "regular criteria" may not be correct, since only one of the two cardinal features: conjunctival injection and tearing may be present (and not both); in other words: "and/or", and not only "and" (in this context, this is termed a "New proposal"; Table 3). Then follows what may seem to be a lack of coherence: The term 'SUNCT' seems to be blamed for allowing the conjunctival injection/tearing combination. One matter must be clear: The term 'SUNCT' per se is neutral in this context; it only 
enumerates the features; it does not combine them. The combination in the diagnostic context has been done by the classification committee itself, in the IHS "regular criteria" (International Classification of Headache Disorders 2004). Nor does the term 'SUNCT' put any boundaries upon how many of the autonomic factors should be obligatory: In the term, two are mentioned; in the title, four; and as mentioned (see above), it could be $\geq$ five.

Another major shortcoming of the "regular criteria" is that, in an incomprehensible way, the autonomic phenomena from 2 to 5 (rhinnorrhea, etc) simply are left out as regards SUNCT (Table 3). There is no rationale behind this. All three unilateral headaches, specified in Table 3, seem to exhibit similar autonomic phenomena, at least outwardly; if anything these phenomena are most marked in SUNCT. The dispositions made by the classification committee in these respects may appear to be totally unacceptable (Such shortcomings, by the way, partly also pertain to $\mathrm{CPH}$; Table 3 ).

If only one of the whole array of autonomic features is present (eg, tearing), the diagnosis may be jeopardized. In particular, it can be imperiled if the only feature is a dubious one, like eyelid edema. "External" edema, additionally to the palpebral edema, is rare in a recognizable form and is hard to ascertain. Nor will eyelid edema be linked to the solitary attacks because the attack duration is too short for that. There is no precedence for edema as a solitary, autonomic symptom in SUNCT. It is possible that the intraocular, vascular phenomena registered by dynamic tonometry (see above) amount to being of diagnostic value in SUNCT. However, dynamic tonometry cannot be expected to have an absolute power, since headaches like $\mathrm{CPH}$ join in. But dynamic tonometry findings may be sine-qua-non features in SUNCT.

Conjunctival injection is presumably an adequate, autonomic phenomenon. It may be a reflection of the fundamental intraocular, vascular phenomena. At this stage, it cannot be excluded that tearing can be the sole autonomic feature, but this is a more dubious situation, since there then is no allusion to the fundamental, intraocular vascular derangement.

The presence of only one autonomic feature such as tearing in the framework of SUNCT should, therefore, primarily be assessed in one of three ways (and in this sequence): Either: Other autonomic features are present, but have escaped detection. Or: The patient has been observed for too short time to allow for the development of other autonomic features. Or: The possibility of a headache of an essentially different nature should be entertained. Considerable energy should be spent on the two first-mentioned alternatives before adopting the last one.
In our first SUNCT case (case 1; Sjaastad et al 1989), a unilateral, low-grade, more or less continuous headache was after close to 30 years transformed into typical, short-lasting paroxysms of more severe pain. It would be utterly strange if a headache of an essentially different nature replaced the original one, in just the same area. The rareness of SUNCT makes this highly unlikely. The headache during close to a generational period in all probability was a disorder of the same nature as the late, recognizable one; it had only not been fully developed. If so, the early stage does not deserve a particular designation, whether it stays oligosymptomatic or, later, develops into a full-blown picture. The early stage would be an oligosymptomatic SUNCT. To make a comparison with the term 'pneumonia', a pneumonia can be global; it can also be lobar and it can even be segmental. But all are pneumonias; they do not need different designations. The moral should be: When one encounters a symptompoor, putative SUNCT case, one should adopt an attitude of wait-and-see for a prolonged period. If anything, the early, atypical stage would be only a "subgroup of SUNCT" and not the other way around.

It should be in the interest of all parties to rectify the situation as regards the autonomic features in SUNCT. The best way to solve the rather precarious and unwary situation, created by the IHS, would seem to be to specify all the autonomic features that are also under SUNCT "regular criteria" just as in cluster headache and CPH (Table 3). The text for features 1) and 2) should be the same for all three headache categories, since there is no reliable evidence for distinguishing between the three headaches as regards these features (Table 3). Presence of the three last features (nos. 3-5; Table 3) will support the diagnosis. As far as we know today, the presence of only one of the last three features will not necessarily suffice as solitary evidence for SUNCT. The demands as regards diagnosis will have to be extremely carefully worded. There is no way around that.

\section{Trigeminal neuralgia (V I tic) and autonomic phenomena}

SUNCT is characterized by an array of autonomic features and V I tic by a paucity of such features, each of them at that occurring rarely. The autonomic features actually are crucial in distinguishing SUNCT from V I tic. The presence of the three cardinal, autonomic symptoms and signs: conjunctival injection, tearing, and rhinorrhea was compared in 19 cases of SUNCT and V I tic, respectively (Sjaastad et al 1997) (in other words: $19 \times 3=57$ being the maximum figure for the three autonomic symptoms in each 
Table 3 Autonomic phenomena in cluster headache, CPH, and SUNCT, according to the International Headache Society Classification Committee (2004)

\begin{tabular}{|c|c|c|c|c|}
\hline & \multirow{2}{*}{$\begin{array}{l}\text { Cluster } \\
\text { headache }\end{array}$} & \multirow[t]{2}{*}{$\mathrm{CPH}$} & \multicolumn{2}{|l|}{ SUNCT } \\
\hline & & & $\begin{array}{l}\text { "Regular } \\
\text { criteria" ' }\end{array}$ & $\begin{array}{l}\text { “New proposal" ' } \\
\text { (or "SUNA") }\end{array}$ \\
\hline \multicolumn{5}{|l|}{ Autonomic phenomena } \\
\hline $\begin{array}{l}\text { I. Conjunctival injection } \\
\text { and/or tearing }\end{array}$ & + & + & $\begin{array}{l}+ \\
\text { only “and”; } \\
\text { "or" omitted }\end{array}$ & + \\
\hline $\begin{array}{l}\text { 2. Nasal congestion } \\
\text { and/or rhinorrhea }\end{array}$ & + & + & - & + \\
\hline 3. Eyelid edema & + & + & - & + \\
\hline 4. Forehead and facial sweating & + & + & - & - \\
\hline 5. Miosis and/or ptosis & + & + & - & - \\
\hline \multicolumn{5}{|l|}{ Diagnostic requirement } \\
\hline At least one of the features: $I-5$ & of the featur & & & \\
\hline
\end{tabular}

Notes: 'The International Classification of Headache Disorders 2004.

Abbreviation: $\mathrm{CPH}$, chronic paroxysmal hemicrania.

of the two headaches). The mean figure for SUNCT was: 50/19, ie, 2.63 (symptoms for each patient), and for V I tic $13 / 19$, ie, 0.68 ( $P<0.0000005$, chi square test). If these three major diagnostic criteria are made nonobligatory, eg, in case eyelid edema is acknowledged as an adequate, solitary autonomic feature (cf. Table 3, "New proposal"), can one rely upon the SUNCT diagnosis any more? If a solitary - and questionable - autonomic feature suffices, then the main barrier - diagnostically towards V I tic may disintegrate. There may presently be no other, trustworthy clues that can replace the triad of conjunctival injection/ tearing/rhinorrhea in SUNCT. And SUNCT diagnosis should be trustworthy, based on positive evidence, and not only conjectural.

\section{Number of daily attacks; refractory period}

According to the "New proposal" (The International Classification of Headache Disorders 2004; "Appendix"), the number of daily SUNCT attacks is: $\geq 1$, whereas in the current, "regular version" the range is stipulated as 3-200 attacks. An important issue as regards SUNCT diagnosis is the high number of daily attacks, equaled only by V I tic (among the unilateral headaches), as far as we know today. And: What counts in SUNCT diagnostics is the maximum number of attacks, not the minimum number. A frequency description of 1 day is, therefore, hardly an illuminating type of guideline for the freshman in the search for a SUNCT diagnosis. According to the IHS, even CPH may seem to have a higher number of daily attacks (ie, $>5 /$ day) than SUNCT, a close to meaningless situation. The "New proposal" for SUNCT diagnosis may simply not be applicable in this respect. An acceptable procedure would seem to be to spell out normative frequency figures for SUNCT, and then add, as has been done for CPH by the IHS: "although periods with lower frequency may occur".

It has been known since our first communication that there may be no, or only a relative, refractory period after solitary SUNCT attacks, in contradistinction to what is the case in V I tic. In the overview from $1997(n=21)$, a refractory period was present "typically" (Pareja et al 1997). The putatively useful diagnostic information of lack of refractory period in SUNCT seems recently to have been recirculated as "new".

\section{"SUNA"}

Recently, the term 'SUNA' has been forwarded as a possible supplement to or corollary in SUNCT (Table 3) (International Classification of Headache Disorders 2004). This term and the following case study (Volcy et al 2005) should be viewed in the broad light of the aforementioned comments on the term. An early case of so-called SUNA has been presented, without any question mark attached. The patient, an 11-year-old girl (the mean age of onset in an overview $(n=21$; Pareja et al 1997) was 50.7 years and the youngest 23-years-old), with chronic complaints from the onset, with up to 15-30-minutes (timing of 348 attacks [Pareja et al 1996]; mean duration: $60.6 \pm 35.7$ seconds; range 24-125 [unweighted values]), heavy attacks and without any attack-precipitating mechanisms, had no refractory period. Tearing was claimed to be the only local, autonomic feature. It is somewhat enigmatic how the lack of refractory period was established in the absence 
of precipitation mechanisms. A diagnosis does not seem to have been established in this case.

The number of counter-arguments against the term 'SUNA' (or: "New proposal") is actually legion. It is hard to grasp that there is a need for two terms for one and the same, well-defined disorder. The "New proposal" (Table 3) seems fictitious and also has an illogical and un-rightful origin. It should be abandoned, also for the sake of clarity.

\section{Concluding remarks}

Forehead sweating, as an example, is present from the beginning of the attack, and predominates on the $\mathrm{S}$ side. No supersensitivity phenomena have been observed. Accordingly, there is most likely a direct stimulation of the sweat glands. This combination of features can probably best be explained by a neurogenic mechanism (with release of vasoactive substances in the periphery) and not by a stimulus transmitted via the blood stream. Analogous reasoning can be applied for CIP amplitudes, etc.

The principal aim of the present communication was to address this early work. The work of other research groups, therefore, generally falls outside the scope of the present article. To put the early findings into proper perspective, one aspect will, nevertheless, be commented upon: SUNCT has over the years acquired a reputation of being refractory to therapy. In recent years, evidence has been obtained to the effect that blood flow to the posterior hypothalamus is enhanced during the SUNCT attack. One subsequent event may represent sort of a breakthrough in SUNCT (Leone et al 2005): In a SUNCT patient with severe complaints, attacks were largely controlled by deep brain stimulation (posterior, inferior hypothalamus), at least on the face of it. For two years preoperatively, there had been $>1000$ attacks per month. The patient had no attacks for prolonged periods postoperatively. However, pain freedom, at times, continued even without stimulation. Also for the latter reason, the stimulation study needs corroboration. Nevertheless, electrical stimulation, apparently interferes significantly with pain perception in this case. Given the fundamental role that hypothalamus plays in the regulation of autonomic functions, it is a distinct possibility that this area of the hypothalamus also is a site of primary importance in SUNCT; but hypothalamus could also, in theory, function as a "relay" station, the input being increased. Neither the presence of increased local blood flow nor the stimulation result can prove which alternative is the underlying abnormality. The localization of the hyperperfusion was a necessary prerequisite for the stimulation study. At this stage, however, the efficacy of stimulation studies would probably be as significant as the activation studies in further mapping out SUNCT pathogenesis.

\section{Acknowledgments}

A tribute is paid to fellow investigators, without whose endeavors there would have been no SUNCT syndrome. Prof. I. Hørven; Prof. D. Russell; Prof. C. Saunte; Dr. P. Kruszewski; Dr. J. Pareja; Dr. J. M. Shen; Dr. J-M. Zhao; Dr. K. Fostad; Dr. T. A. Fredriksen; and Prof. R. Salvesen. The author reports no conflict of interest.

\section{References}

Aaslid R, Brubakk AO. 1981. Accuracy of an ultrasound Doppler servo method for noninvasive determination of instantaneous and mean arterial blood pressure. Circulation, 64:753-59.

Aaslid R, Markwalder T-M, Nornes H. 1982. Noninvasive transcranial Doppler ultrasound recording of flow velocity in basal cerebral arteries. J Neurosurg, 57:769-74.

Bussone G, Leone M, Volta GD, et al. 1991. Short-lasting, unilateral neuralgiform headache attacks with tearing and conjunctival injection: the first "symptomatic" case. Cephalalgia, 11:123-7.

Hardy P, Bowsher D. 1989. Contact thermography in idiopathic trigeminal neuralgia and other facial pains. Br J Neurosurg, 3:399-402.

Headache Classification Subcommittee of the International Headache Society. 2004. The international classification of headache disorders. Cephalalgia, 24(Suppl 1):1-160.

Hørven I. 1970. Dynamic tonometry II. Methods of corneal indentation pulse registration. Acta Ophthalmol (Kbh), 48:23-38.

Hørven I, Nornes H, Sjaastad O. 1972. Different corneal indentation pulse pattern in cluster headache and migraine. Neurology, 22:92-8.

Hørven I. 1975. Corneal temperature in normal subjects and arterial occlusive disease. Acta Ophthalmol (Kbh), 53:863-74.

Hørven I, Larsen CT. 1975. Contact probe for corneal temperature measurements. Acta Ophthalmol (Kbh), 53:856-62.

Hørven I, Russell D, Sjaastad O. 1989. Ocular blood flow changes in cluster headache and chronic paroxsysmal hemicrania. Headache, 29:373-6.

Kruszewski P, Fasano M, Brubakk AO, et al. 1991. Short-lasting, unilateral neuralgiform headache attacks with conjunctival injection, tearing, and subclinical forehead sweating ("SUNCT syndrome): II Changes in heart rate and arterial blood pressure during pain paroxysms. Headache, 31:399-405.

Kruszewski P, Sand T, Shen JM, et al. 1992. Short-lasting, unilateral, neuralgiform headache attacks with conjunctival injection and tearing (SUNCT syndrome): IV. Respiratory sinus arrhythmia during and outside paroxysms. Headache, 32:377-83.

Kruszewski P, Zhao J-M, Shen JM, et al. 1993. SUNCT syndrome: forehead sweating pattern. Cephalalgia, 13:108-13.

Kruszewski P, White L, Shen JM, et al. 1995. Respiratory studies in SUNCT syndrome. Headache, 35:344-48.

Leone M, Franzini A, D’Andrea G, et al. 2005. Deep brain stimulation to relieve drug-resistant SUNCT. Ann Neurol, 57:924-7.

Nilsson GE. 1977. On the measurement of evaporative water loss. Linkøping University Medical Dissertations. No 48. Linkøping, Sweden.

Pareja JA, Shen JM, Kruszewski P, et al. 1996. SUNCTsyndrome: Duration, frequency and temporal distribution of attacks. Headache, 36:101-5.

Pareja JA, Sjaastad O. 1997. SUNCT syndrome. A clinical review. Headache, 37:195-202.

Russell D. 1978. Measurement of the pain-threshold and pain-tolerance in a cluster headache population. In: Proceedings of the Scandinavian Migraine Society, p. 27.

Salvesen R, Bogucki A, Wysocka-Bakowska M, et al. 1987. Cluster headache pathogenesis: A pupillometric study. Cephalalgia, 7:273-84. 
Salvesen R. Sand T, Sjaastad O. 1988. Cluster headache: Combined assessment with pupillometry and evaporimetry. Cephalalgia, 8:211-18.

Shen JM, Johnsen HJ. 1993. SUNCT syndrome: Estimation of cerebral blood flow velocity with transcranial Doppler ultrasonography. Headache, 34:25-31.

Sjaastad O, Russell D, Hørven I, et al. 1978. Multiple, neuralgiform, unilateral headache attacks associated with conjunctival injection and appearing in clusters. A nosological problem. In: Proceedings of the Scandinavian Migraine Society, p. 31.

Sjaastad O, Saunte C, Russell D, et al. 1981.Cluster headache. The sweating pattern during spontaneous attacks. Cephalalgia, 1:233-44.

Sjaastad O, Saunte C, Salvesen R, et al. 1989. Shortlasting, unilateral neuralgiform headache attacks with conjuctival injection, tearing, sweating and rhinorrhea. Cephalalgia, 9:147-56.
Sjaastad O, Kruszewski P, Fostad K, et al. 1992. SUNCT syndrome: VII. Ocular and related variables. Headache, 32:489-95.

Sjaastad O, Pareja JA, Zukerman E, et al. 1997. Trigeminal neuralgia. Clinical manifestations of first division involvement. Headache, 37:346-57.

Vijayan N, Watson C. 1984. Corneal sensitivity in cluster headache. Headache, 24:162.

Volcy M, Tepper S, Rapoport AM, et al. 2005. Short-lasting unilateral neuralgiform headache attacks with cranial autonomic symptoms (SUNA) - a case report. Cephalagia, 25:470-2.

Zhao J-M, Sjaastad O. 1993. SUNCT syndrome:VIII. Pupillary reaction and corneal sensitivity. Funct Neurol, 6:409-14. 
